\title{
Supporting Design and Technology Lessons with the Use of Problem-Based Learning
}

\author{
Abdul Azim Mohamed Sambas \\ School of Energy and Engineering, \\ IBTE Mechanical Campus, Brunei Darussalam \\ Masitah Shahrill \\ Masriatol Zuraifah Sajali \\ Sultan Hassanal Bolkiah Institute of Education, \\ Universiti Brunei Darussalam, Brunei Darussalam
}

\begin{abstract}
This study implemented the use of Problem-Based Learning (PBL) in Design and Technology lessons. The investigation involved students' attitudes towards PBL. PBL is said to enhance students' understanding and provide them with meaningful learning experience. The participants for this study were seven Year 11 students consisting of two males and five females from a secondary school in Brunei Darussalam. Data were collected using instruments such as pre- and post-tests, observation list, participant observation, reflection and interviews. The study found there were improvements in the collaboration between the students. They had the opportunities to think creatively to generate ideas for their project. Students' attitudes became more positive with the implementation using PBL. It is suggested that future teachers to use this method. However, teachers' confidence in using the PBL method will need to be further enhanced.
\end{abstract}

Keywords: Problem-Based Learning; Design and Technology; Secondary Schools

\section{Introduction}

Problem-Based Learning (PBL) was officially adopted as a pedagogical approach in 1968 at McMaster University, Canadian medical school because students were unable to apply their substantial amount of basic scientific knowledge to clinical situations (Barrows, 1996). During PBL, students will do an independent study to find a solution through journal articles, the library, the Internet, brochures and resources from people. According to Richards and Cameron (2001), the use of PBL is ideal with group work which involves brainstorming, sharing of ideas, and teamwork. Newman (2003) stated that PBL has been used as part of a teaching strategy in many professional fields including medicine, nursing, dentistry, social work, management, engineering and architecture. Moreover, this teaching strategy has also been implemented in the teaching of school subjects such as mathematics (Adnan \& Shahrill, 2015; Ahamad et al., 2018; Botty \& Shahrill, 2014, 2015a, 2015b; Botty et al., 2016; Han et al., 2016) and geography (Caesar et al., 2016) to support the learning development of the secondary school students in Brunei Darussalam.

Even though there are many different models of PBL, all seemed to provide similar definition and provided some evidence of the positive effects of using PBL. PBL is a student-centered pedagogy which involves student learning about a subject through experience of problem solving including solving a real life problem (Correnti, 2014). Based on a study by Utecht (2003), he stated that PBL maximizes students' involvement in the learning process and students may apply the knowledge they learn in helping them to solve real-world problems. Therefore, students are keener to learn hence turning them into lifelong learners.

Mustapha and Rahim (2011) stated that PBL is one of the learning methods that use relevant and meaningful real-life problems as its foundation. In fact, PBL according to Saleh et al. (2017) may be an effective method to expose the students on gaining work experiences while still studying. Meanwhile Gomez-Ruiz et al. (2009) stated that PBL is an approach to 
structuring the curriculum, which has been derived in an educational technique that confronts the students with problems from practice, providing a stimulus for learning. Furthermore, PBL is not merely a teaching and learning technique but a total approach to education (Barret, 2005). Therefore, it reveals that PBL is an approach on how to make us think critically and be independent on solving real-life problems. PBL also develops higher order cognitive skills where learning is initiated through a real problem that has engaged the learner to find its solution. PBL also works better within a group work setting (Richards \& Cameron, 2001) because it helps and motivates students to identify, apply, collaborate and communicate their knowledge efficiently. This is also supported by Sedaghat et al. (2018) research on using PBL method, the students work collaboratively as a team and they manage to build their product according to the specifications needed. Both team from that study produced different style of product yet satisfying the requirements.

PBL will help students think critically, be more responsible and more independent rather than the teacher giving the answer or solution to the students. The students will have to realize that they have to be active thinkers on how to solve problem, finding solution through the Internet, books, journal, article and etc. According to Selçuk and Çalışkan (2010), PBL is an effective teaching method in comparison to a traditional method of teaching. He added that PBL lets teachers facilitate students, teachers and students evaluate learning together, and learning is assessed directly through papers, projects, performances, portfolios.

Utecht (2003) stated that student-centered learning consisted of a classroom where the students are actively involved in the learning process. Furthermore, Utecht mentioned that the students must get involved, interact and socialize to make sure the job can be done, let the students have the opportunities to confront new information and experience without the dominance of a teacher giving the information and students' knowledge are highly individualized for them to be adapted based on their style and pace for learning. Therefore, student-centered learning is a method of learning or teaching that puts focus on the students whereas problem-based learning involves students solving real-life problems. The relation between these two is that the students would be given a problem to be solved and teachers only need to facilitate their learning. Hence, a student-centered learning is produced.

There are requirements before using the PBL approach. According to Gomez-Ruiz et al. (2009), teachers need to conduct the following: The problem should relate to the subject matter and using a real-life problem; the problem should be designed with multiple stages to work step by step; to make the students realize that individual work is not a good strategy to figure out the solution, thus group work is required; the first problem should relate with the prior knowledge of the student; and the objectives of PBL should be included. This is considered part of the planning process before using PBL to be applied in a Design \& Technology (D\&T) lesson. When using PBL, Richards and Cameron (2001) stated that it is best to work in groups.

\section{Effectiveness of Problem-Based Learning (PBL)}

Mustapha and Rahim (2011) stated that most teachers preferred traditional teaching method because it is a more suitable method than student-centred method when the focus is on the examination and the class size is mostly large. However, there were many weaknesses of the traditional teaching method. One of the weaknesses is the lack of interaction between the students and teacher. Thus, PBL is one of the teaching methods that allow more interaction among the students compared to traditional method. PBL focuses on active learning which involves the minds and hands. Throughout the teaching of using PBL, Mustapha and Rahim (2011) found out that the students' collaborative skills had improved; results and grades became better and positive attitudes towards PBL observed. In their study, Selçuk and Çalışkan (2010) found that using PBL showed an improvement in students' active engagement in the learning activities. Subsequently, using PBL also improved the students' attitudes towards learning.

\section{Model of Problem-Based Learning (PBL)}

To use PBL in the classroom, there is a need to understand the model of PBL. According to Gomez-Ruiz et al. (2009), the basic model normally involves few steps as: (1) Presenting the problem to the students. Then the students form a group and share their thoughts about the problem that is given, (2) Discussion session takes place where the students discuss among their group, ask questions, share their knowledge on what they know regarding the problem, (3) Discussion with and guidance from the teacher about the problem that they do not understand, and (4) Exploration where students do their own research (books, article, journal, Internet and etc.) in order to solve and find the solution of the problem. 
Gomez-Ruiz et al. (2009) also stated that the basic model might only be applicable to some lesson. This is why there are various types of PBL model to ensure that the model is applicable to that D\&T. Meanwhile, Barrett (2005) introduced his PBL model, which includes the following steps:

Students are presented with real-life problem.

Students are to discuss the problem with a small group in the PBL tutorial. They clarify the facts of the case. They define what the problem is. They brainstorm ideas based on their prior knowledge. They identify what they need to learn to work on the problem, what they do not know (learning issues). They reason through the problem. They specify an action plan for working on the problem.

Students engage in independent study on their learning issue outside the tutorial. This includes library, Internet, resource from people and observation.

They come back to the PBL tutorial sharing information, peer teaching and working together on the problem.

They present their solution to the problem.

They review what they have learned from working on the problem. All who participated in the process engage in themselves, peer and the tutor review the PBL process and reflect on each person's contribution to that process.

As such, the PBL model revolves within the action research (Hussey et. al., 2011). PBL use models as a guide to help in the planning process. Once the planning process is done, a chosen PBL model is implemented in the teaching strategy. The pre- and post-tests are used to monitor the students' improvement in the assessment paper before and after the PBL intervention in order to observe their critical thinking skills. Furthermore, during the acting process, the teacher observed the students' behaviors and responses. This is done through using both participant observation and observation list that looks at whether PBL supports collaboration skills, communication skills and creativity skills. At the end of the process to action research, both students and the teacher need to reflect and evaluate what has been learnt. By using interviews, students' opinions on using PBL in the process can be gathered. There are many ways to collect the data hence for this particular study; this is how action research can contribute to PBL.

\section{The Study}

The Design and Technology (D\&T) is a subject offered in secondary schools in Brunei Darussalam as an optional subject. In Brunei, D\&T follows the International General Certificate of Secondary Education (IGCSE) syllabus. According to the IGCSE syllabus, D\&T focuses on design actions and the application of knowledge and process skills. Students are to engage in design and create activities and experience a basic process of design adapted to their abilities, interest and design context. Most questions in the D\&T exam papers require students to think and solve real-world problems. For that reason, the PBL could be used to develop those skills (Mustapha \& Rahim, 2011).

The aim of this study is to investigate the use of PBL in the teaching and learning of D\&T. These are the research objectives: To improve the teaching and learning of lessons in D\&T, assess how well the students work in groups when they solve problems - this is to improve their teamwork with peers, and to suggest ways to improve in identifying and solving the problem in their design by being independent and less guided by the teacher. This study is guided by the research question; to what extent can PBL support Year 11 student learning of Design and Technology?

\section{Limitation of the Study}

This is an action research study on a D\&T class of seven students. The small sample size might be seen as a limitation to research of the quantitative nature. However, the purpose of the study was not to generalize the findings. Rather, this action research study aims to improve the students' learning and more importantly, the study will provide a better understanding of the use of PBL in teaching D\&T. Due to the limited available contact time with the students, the study was only conducted within a short period of time. 


\section{Methodology}

In order to determine the extent of the use of PBL in the lesson, it is important to select an approach that facilitates the study. In this section, the research design and action research approach will be elaborated. Following this, the data collection method is explained.

\section{Research Design (Planning Stage)}

Figure 1 below shows the flow chart on how the procedure will take place during the teaching using the PBL.

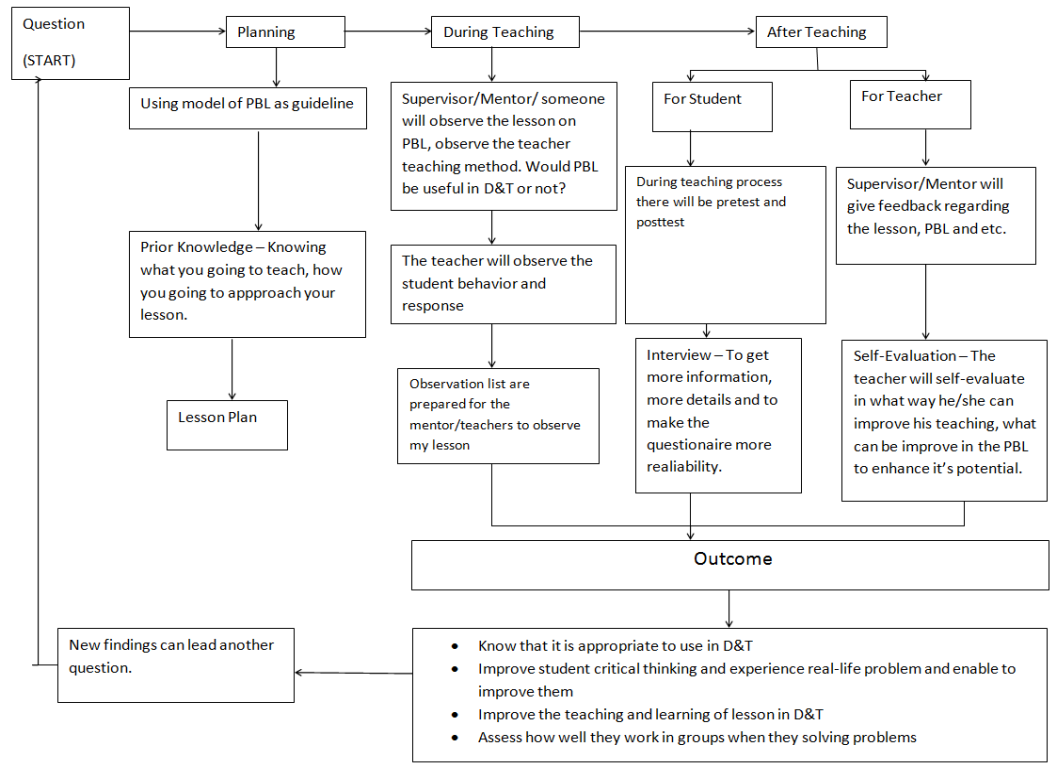

\section{Figure 1: Flowchart of the Research Design}

FIRST STAGE QUESTIONS: The question/problem is mostly based on the IGCSE Design and Technology exam paper.

SECOND STAGE PLANNING: Planning involves decision-making on which model to use, students' prior knowledge in order to know what to teach and how to approach students and planning the lesson. This study used Barrett's (2005) PBL model. A PBL lesson plan was prepared a week before the actual lesson plan with guidance by the Head of Department in D\&T. The observation list and question paper were printed early.

THIRD STAGE DURING TEACHING: An hour before the lessons, the observer (mentor/teachers) was briefed on what will happen during the lesson and what the observer will be doing. The observer will be given an observation list and lesson plan. The lesson on PBL will be done according to the Barrett (2005) PBL model.

FOURTH STAGE AFTER TEACHING: For the student part, a post-test will be administered in the next lesson in the morning and the interview in the afternoon. For the teacher part, the observer will comment on his/her thoughts about the lesson and the students' responses during the lessons. Self-evaluation and reflection on the lesson is essential for this study.

FINAL STAGE: The pre-test, post-test, observation and interview will be analyzed. The results need to meet the objectives of the research, which are to enhance Year 11 students' learning and teaching of D\&T. Depending on whether the results coincide with the objectives or not, the whole process can be circulated again hence it can be seen to be similar to action research. 


\section{Action Research}

Action research can be known by many names such as 'practitioner enquiry', 'reflective analysis' or 'evidence-based practice' but all gives the same definition and can be defined as learning by doing. O'Brien (2001) defined action research which a group of people identify a problem, do something to resolve it, see how successful their efforts were, and if not satisfied, try again. Gilmore et al. (1986) stated that,

Action research is to aim to contribute both to the practical concerns of people in an immediate problematic situation and to further the goals of social science simultaneously. Thus, there is a dual commitment in action research to study a system and concurrently to collaborate with members of the system in changing it in what is together regarded as a desirable direction. Accomplishing this twin goal requires the active collaboration of the researcher and the client, and thus it stresses the importance of co-learning as a primary aspect of the research process. (pp. 160-176).

This study used the basic principle of action research based on Leslie (2005) called the 'four-phase cycle' adapted from The Open University as shown in Figure 2.

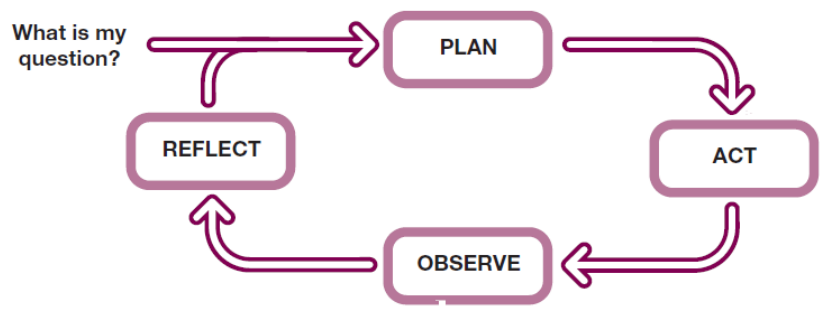

Figure 2: Four-Phase Cycle based from Leslie (2005) adapted from The Open University

According to Leslie (2005), the action research process is often described as:

Cyclical with four inter-related stages: Plan, act, observe and reflect, as depicted on Figure 2 above.

Collaborative as it involves not just the researcher himself, but a group of teachers working together

Usually qualitative compared to quantitative with the emphasis of getting an in-depth understanding of the situation in question.

Reflective, involving critical reflection on both the process and outcomes of the study.

Action research always begins with an issue, and based on our observations, the students lack the ability to solve problems when using the traditional teaching method. The first step in each cycle of action research process involves planning. Planning involves the preparation and planning process that include the making of the lesson plan, what teaching aids will be used during the lesson, what other resources will be used, stating the objectives of the lesson type of model that's going to be used in PBL. For this study in particular, the first author conducted the lesson, and two teachers assisted with the planning process and data collection for the PBL. Subsequently they gave comments and provided feedbacks on how the lesson can be improved based on the planned lesson and teaching. During the second and third step of the cycle the use of PBL was then incorporated in one of the lessons. While conducting this approach, the teachers observed the students based on the observation list shown in Figure 3, which included student responses and behavior during class. In addition, observations were made by focusing on how the PBL was enacted in class and the students' performance on the given work. Meanwhile, the final step in this cycle reflected critically on the whole process. In order to gain an understanding of the students' perceptions of the use of PBL, each of the students were interviewed based on a semi-structured format.

The action research process is rarely a simple cycle but it is often spiral. Reflection on the last lesson contributed to the findings of this study, which may lead to further action, and usually a change in the classroom practice, which consequently leads to further exploration of the issue in question. Thus, it may involve several cycles addressing the same issue. However, in this study there was a limited time to conduct several cycles. 


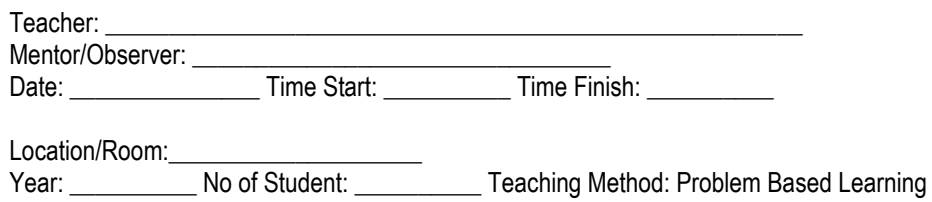

Location/Room:

Year: No of Student: Teaching Method: Problem Based Learning

1. What activity/task was given to the students? Comment on the activity?

2. Do the students stayed on their activity/task? Explain?

3. Do the students share the ideas, teamwork and support each other? Explain?

4. How are the students undertaking the activity?

5. How are the students behaving?

6 . What resource the student use and how does that resource help them?

7. Do the students appear more motivated, engaged or better prepared?

8. Do all the students contribute their idea? Explain?

9. Do the students show motivation when doing the activity? Explain?

10. Does and Why the activity will help the student to prepare them for the design paper question?

11. Is there any limitation, difficulties and improvement for the activity and teacher? Comment?

12. Does the teacher give clear explanation/instruction what should the student will be doing?

13. Does the teacher manage the time well to do the activity $(\mathrm{PBL})$ or more time is needed?

14. Does the teacher evaluate the outcome of the student work? Comment?

15. Is there any comment would you like to add regarding the student learning and behavior, teacher teaching and the PBL activity weather its help them or not? (Observer Overall Comment)

Observer Signature:

Date:

\section{Figure 3: The observation list}

\section{Data Collection}

\section{Participants}

The study was conducted in a Year 11 D\&T lesson at one of the secondary schools in the Brunei-Muara District. The participants consisted of two males and five females, as it is only the sample that was accessible. Importantly, this Year 11 class was the only D\&T class available in the school. This class was scheduled for five lesson periods per week, and each period lasted for half an hour.

\section{Pre-test and Post-test}

The pre-test evaluated the students' knowledge of a subject before they cover the material whilst the post-test was given after the material had been covered. The questions used on both tests were from the past year examination papers. The reason why the past examination papers were used was to prepare the students for the actual upcoming examinations. 


\section{Classroom Observation}

Flick (2009) mentioned that there are various types of qualitative research such as participant observation, in-depth interviews and focus groups that are the most commonly used methods in applied qualitative inquiry. Therefore, the participant observation was conducted in order to observe their behavior during the PBL lesson. Using a semi-structured observation guide, the observation list was used to observe the students' behaviors during the PBL lesson, to see how the students respond and what their attitude are towards PBL.

\section{Reflection}

In the final cycle of action research, which is reflect, it is essential for the teacher to reflect on his/her lesson for using PBL to see whether the teacher's teaching has improved. From here, information was gathered if PBL helped to achieve the lesson objective and most importantly can the students learn better when teaching them using the PBL technique.

\section{Interview}

There are many types of interview that can be used, however for this study the 'General Interview Guide Approach' were utilized. Turner (2010) stated that a general interview guide approach is more structured than the informal conversational interview although there is still quite a bit of flexibility in its composition. Turner (2010) also mentioned that using this general interview guide approach it allows the opportunity to develop a rapport with the participants because the questions can be changed based on their responses which could explore more into a personal approach related to the topic. Therefore, the reasons in using this interview were to investigate whether PBL is applicable to be used in during the D\&T lesson, to observe students' responses and behavior towards PBL. Since there is only a small sample of students taking D\&T, all the seven students were interviewed after the post-test had been distributed and collected.

\section{Data Analysis}

Referring back to the research question, to what extent problem-based learning could support Year 11 students learning of design \& technology, the data gathered and analyzed were from the pre- and post-tests, the PBL lessons, classroom observation, teacher reflection of teaching using PBL and from the interviews.

\section{Ethical Consideration}

Permission to conduct the study had been sought well in advance, and subsequently conveyed to the school. This was to ensure that access that had been granted did not violate any ground rules of the school when collecting the data for the study. Consent forms were given to the students in order to obtain their permission to be interviewed. Moreover, students were allowed to withdraw if they decided not to participate in the interview.

\section{Results}

Table 1 below shows the results for the pre- and post-tests. However, these were based on six students only because one student was absent for the post-test.

Table 1: Mean Results of Test

\begin{tabular}{|l|l|l|l|}
\hline & PRE-TEST (\%) & POST-TEST (\%) & DIFFERENCE (\%) \\
\hline MEAN & $53.6 \%$ & $55.3 \%$ & $+1.7 \%$ \\
\hline
\end{tabular}

According to the Table 1 above, there is only a small percentage of improvement between the two tests. Based on the posttest responses, the students gained or lose marks from the orthographic drawing but achieved almost full marks on the theory section. The drawing and sketching part were the ones that hold the most marks in the assessment paper. When the students were assessed individually, 4 out of 6 students showed an improvement on their post-test. During the PBL lesson, some students were extrovert and some were introvert, which indicated that some students contributed their ideas during the discussions and some kept quiet since they did not contribute any ideas. 


\section{Classroom Observation}

\section{Participant Observation}

As the first author was explaining the objectives for that day's particular lesson, all the students were excited because the lesson was something new for them. Discussions began after the problem was presented. At first, there were not a lot of responses when the questions were asked, so a simpler question was posed, such as "what can you see in the picture?" and slowly there were responses from each of them. The quieter students were asked more questions so that they can be given more opportunities to participate in the discussions. All the students knew that they needed to design a workstation but they left out one important key point or fact, which the teacher mentioned that the workstation itself must easily be transported and/or stored. The problem was to:

\section{"Design a workstation that would be suitable for this hobby (model making) and could be easily transported and/or stored"}

A 5 to 10 minutes discussion was not enough. More time was needed at this stage; therefore another extra 5 minutes were spent discussing the problem with the students. Even so a total of 15 minutes was not enough and during the discussion, it was rushed because of the concern of not having enough time. The students engaged in independent study so that they share their information with everyone. The students then presented their solution to the problem. Since there was only one computer available to use (the D\&T computer room was locked), the students did group work instead. There were a lot of difficulties at this stage, especially when some students started talking about other matter when they were supposed to find a solution to their problem task. In order to keep students focused on their task, the following questions were posed: Why have they chosen that design? Why do you choose that material? And how are you going to move that workstation to one place to another? Surprisingly, the students were able to provide responses to these questions, even though the time given for them to engage with their tasks was limited. The lesson followed with the following simple question answer session with the students, such as: Give me one additional point that you think it is important about the function of the work station; What method will you use to make the workstation; Draw a 5 minute sketch of your own design of a workstation; and What material will you use and why?

\section{Observation List}

One of the teachers from the school observed the lesson based on what he saw during the lessons. Furthermore, from his personal observation and from the observation list, he provided the following statements, which proved that utilizing the PBL could make the student think critically and brainstorm ideas, ideas were generated by students, ideas were able to be shared and therefore all students were working as a team and there were significant interactions between each other, and ultimately, the student were able to think outside of the box.

\section{Reflection}

From the first author's point of view, the lesson went well but there were time constraints. Given below is his account of the lesson:

I only have 40 to 45 minutes to conduct my lesson (including the 5 to 7 minutes waiting for the students to enter the classroom and give a brief introduction of what am I going to do today). As I went through the PBL model, each procedure was explained in a rush but I tried to calm myself down because I would like to listen to the students' responses on today's lessons carefully. I received good feedbacks from the students as we were discussing the problem based on the picture they have seen. But as I asked the students to engage on their own research to find the solution to the problem (where they have to find a workstation that can be easily transported and stored), they began to lose focus. They were talking about a different topic instead of focusing on the problem. As a teacher, I tried to make sure that they are focused. By asking questions individually like "have you found a design and why have you chosen this design", the students were able to concentrate on their task again. Since I asked them to do it in a group, I asked all of them to present their designs together. I asked a different question individually and each of them was able to give a good answer. I even asked them to draw a 5 minute sketch of their own design of workstations. Some students were good at sketching and were very detailed as well. During the lesson, I used bilingual language, that is code-switching between the Malay land English languages. This is because I noticed from their reactions that they may not understand what I was talking or maybe the questions were too difficult for them to understand. I could see that some students were extrovert and some were introvert. On a reflection, 
I would want to improve on my questioning, so that I can encourage my students to think critically. Overall the lesson went well as I was following the PBL model accordingly.

\section{Interview}

During the interviews, most students said that the discussion helped them to discover new ideas and solutions to solve the problem. Problems were discussed thoroughly; critical questions were pointed out by asking themselves what material to use, how the design looked like and many more. As we proceeded, the next stage was to ask the students to do research individually using the Internet. It was very useful for the students because it helped them to find different designs where they were able to think critically and able to help them with their drawings. The students must practice repeatedly to draw because it may take 1 to 2 days to be able to draw or sketch. At the end of the interviews, the students were asked if they want the teacher to use PBL as a teaching strategy and why. Given below are the students' responses:

"Yes I do because it trains us to think out of the box and also by the help of the internet help us to explore and open our mind on the given problem." (Student 1)

"Yes I think I want because Easy to understand, sharing of thoughts (brainstorm), doing research in the Internet." (Student 2)

"Yes because... I don't know [nda tau]" (Student 3)

"Yes because I think it is effective. Effective because there is step by step strategies" (Student 4)

"Yes because it helps me" (Student 5)

"Yes, because I want to know what my member want to comment on my design to improve my design" (Student 6)

From the above responses, utilizing PBL in the lesson shows a positive impact on the students' learning even though there were only slight improvements from the students' post-test results. It can be concluded that PBL helps the students to think beyond the norm, it helps them to solve problems, improve on their creativity in creating new designs, and also helped them to work and brainstorm ideas with their peers.

\section{Discussion}

The results from all the data that had been collected, it proves that PBL was able support the Year 11 students in their learning of design and technology. Utecht (2003) mentioned that students learn best when they are engaged in the learning process and discover in them the meaning of knowledge. PBL, a student-centered method provided the opportunities to discover knowledge in a meaningful and applicable way. Although the average difference shown in the pre- and post-tests was minimal, the data obtained from the observations and interviews illustrated the increase in students' engagement.

In their study, Gomez-Ruiz and colleagues (2009) found that the main outcome of using PBL was the meaningful experience, where students worked in collaborative groups making decisions and responsibilities together. The findings from this present study concur with that of Seaghat et al. (2018), where the students experienced working together collaboratively with their friends, share ideas and making decisions on designing the product. Among the results of this study as well, the observer mentioned that students shared their ideas with their friends. PBL allows students to develop their collaboration skills, through sharing ideas, thoughts and design during discussions. Similar results were shown in Mustapha and Rahim (2011) study where collaborative skills improved and showed positive attitudes towards problembased learning.

Referring to the observation list earlier, the observer mentioned that the students were able to think outside the box as well as training the students in a problem solving type of questions that allowed them to generate their ideas and options to a higher capacity. This proves that the students were able to think critically and brainstorm some ideas to help them solve the problem. But not all the students were able to contribute ideas productively because of their personality characteristic traits.

Referring back to the Barrett (2005) model, he mentioned that the reason in using PBL is to motivate and help the students to learn, develop students' thinking skill, foster professional competence and confidence together with professional identity and so on. Other researchers such as Mahendru and Mahindru (2011) used a similar model by Barrett (2005) in an 
electronic and communication engineering course student, they mentioned that implementing PBL helps in developing a team spirit, makes student flexible in processing information and handling different problems and freedom so as to express the problem and the solution in one's own approach. They also stated that the PBL increases the students' abilities to direct their own learning. Therefore, the use of the PBL model does improve the teaching and learning of this particular D\&T subject, improve the students' capabilities in teamwork and were able to think critically.

\section{Conclusion}

To answer the research question "to what extent Problem-Based Learning can support year 11 student learning of Design and Technology" and based on the findings of this present study, the PBL can develop students to work as a team, think critically and improve the teaching and learning in the design and technology lesson. It was assumed that the Year 11 D\&T students would score higher in the post-test. Some students showed great improvements on the post-test but as a whole, it shows only a slight $+1.7 \%$ of improvement. Even though it is just a slight improvement, the students were able to achieve teamwork, thinking critically, generate idea creatively by themselves. In addition, results from interviews shows that the students enjoyed the PBL lesson because they were able to communicate with their friends, sharing and brainstorming ideas and respond on the design problem that they were given. Most students enjoyed the presentations stating that it could improve their communication skills. Furthermore, utilizing the PBL in the lesson helps them to be more creative on their design thus improving their drawing skills, although the skills to draw well still needs more practice and repetition in order to achieve more improvement.

\section{Recommendations for Future Research}

Based on the findings and limitations of this present study, although there were only slight improvements from the assessment intervention tests, we can still see a positive impact on the learning process. The use of PBL can be part of other teachers' teaching strategy but it will be advisable to go for further training or seek guidance from those who regularly uses PBL as their teaching strategy. For the experienced teachers who use PBL as their teaching strategy, they could give workshops for those who are inexperience in using PBL. Furthermore, lectures at the higher education settings should be exposed to PBL and other innovative teaching strategies in different subject areas. Additionally, one should be active in constructing problems according to the lesson objectives because the goal in using PBL is so that students could see the problem in real-life situations where they can see the problem for themselves. If the student is not active, the lesson itself won't be effective in learning.

In order to gain further understanding on the use of PBL in classrooms, it would be beneficial if a team of D\&T teachers could work collaboratively in conducting their lessons using PBL that involves more real-life projects. Investigations can also be done to further study the effects in PBL in other lessons or other subjects. Considering the time constraints, only one cycle of the action research was conducted in this present study. If more time were given, a few more cycles would assist in gaining an in depth understanding on the use of PBL.

\section{Reference}

[1] Adnan, N. H., \& Shahrill, M. (2015). Investigating the efficacy of problem-based learning intervention (PBLI) among lower secondary school students. Poster presented at the $7^{\text {th }}$ ICMI-East Asia Regional Conference on Mathematics Education (EARCOME 7), "In Pursuit of Quality Mathematics Education for All", Cebu City, Philippines, 11-15 May 2015.

[2] Ahamad, S. N. S. H., Li, H-C., Shahrill, M., \& Prahmana, R. C. I. (2018). Implementation of problem-based learning in geometry lessons. Journal of Physics: Conference Series (Vol. 943, No. 1, p. 012008). IOP Publishing.

[3] Barrows, H. S. (1996). Problem-based learning in medicine and beyond: A brief overview. New Directions for Teaching and Learning, 68, 3-12.

[4] Barrett, T. (2005). Understanding problem-based learning. In T. Barrett, I. Mac Labhainn, \& H. Fallon (Eds.), Handbook of enquiry and problem-based learning: Irish case studies and international perspectives (pp. 1326). Galway, Ireland: CELT, National University of Ireland Galway and All Ireland Society for Higher Education. 
[5] Botty, M. R., \& Shahrill, M. (2014). Using structured problem-based learning to support students' learning in mathematics. Paper presented at the International Academic Forum (IAFOR) Inaugural North American Conference Series for North American Conference on Education (NACE2014), "Transforming and Changing Education: Borderlands of Becoming and Belonging", Providence, Rhode Island, United States, 25-28 September 2014.

[6] Botty, H. M. R. H., \& Shahrill, M. (2015a). Teacher as facilitator: Using structured problem-based learning to support students' learning in mathematics. Paper presented at the $18^{\text {th }}$ International Conference on Education (ICE 2015), "Education in the 21st Century: Present Practices, Future Directions. What's Next?", Bandar Seri Begawan, Brunei Darussalam, 2-4 June 2015.

[7] Botty, H. M. R. H., \& Shahrill, M. (2015b). Narrating a teacher's use of structured problem-based learning in a mathematics lesson. Asian Journal of Social Sciences \& Humanities, 4(1), 156-164.

[8] Botty, H. M. R. H., Shahrill, M., Jaidin, J. H., Li, H-C., \& Chong, M. S. F. (2016). The implementation of problembased learning (PBL) in a year 9 mathematics classroom: A study in Brunei Darussalam. International Research in Education, 4(2), 34-47.

[9] Caesar, M. I. M., Jawawi, R., Matzin, R., Shahrill, M., Jaidin, J. H., \& Mundia, L. (2016). The benefits of adopting a problem-based learning approach on students' learning developments in secondary geography lessons. International Education Studies, 9(2), 51-65.

[10] Correnti, S. (2014). Enhanced problem-based learning through an innovative virtual learning environment: An opportunity for science teachers. In International Conference: New Perspectives in Science Education (pp. 16).

[11] Flick, U. (Ed.). (2009). The sage qualitative research kit: Collection. SAGE Publications Limited.

[12] Gilmore, T., Krantz, J., \& Ramírez, R. (1986). Action-based modes of inquiry and the host-researcher relationship. Consultation, 5(3), 160-176.

[13] Gomez-Ruiz, S., Perez-Quintanilla, D. and Sierra, I. (2009). Problem-based learning: an approach to chemical engineering education within the EHEA. In A. Lazinica, \& C. Calafate (Eds.) Technology Education and Development [online] InTech, 177-190.

[14] Han, S. H., Shahrill, M., Tan, A., Tengah, K. A., Jaidin, J. H., \& Jawawi, R. (2016). Administering problem-based learning (PBL) approach in the teaching of college-level mathematics. Turkish Online Journal of Educational Technology, November 2016, Special Issue for INTE 2016, 197-207.

[15] Hussey, J., Holden, M. T. \& Lynch, P. (2011, Jan). Utilising Action Research to Evaluate Problem-based Learning's Effectiveness. Paper presented at conference of the Action Research Colloquium, Waterford Institute of Technology, Ireland. Retrieved from http://witactionresearch.weebly.com/uploads/6/6/2/4/6624465/husseyj.final.pdf

[16] Leslie, V. (2005). Action Research a Guide for Associate Lecturers. Retrieved from http://repositorio.minedu.gob.pe/bitstream/handle/123456789/3590/Action\%20Research\%20A\%20Guide\%20f or $\% 20$ Associate $\% 20$ Lecturers.pdf?sequence=1\&isAllowed=y

[17] Mustapha, R., \& Rahim, Z. L. A. (2011). Problem-based learning in Malaysian technical school. EDUCARE, 4(1), $41-54$.

[18] Mahendru, P., \& Mahindru, D. V. (2011). Problem-based learning: Influence on students' learning in an Electronic \& Communication Engineering course. Global Journal of Researches in Engineering, Electronic and Electronics Engineering, 11(8), 1-9.

[19] O'Brien, R. (2001). An overview of the methodological approach of action research. In R. Richardson (Ed.), Theory and practice of action Research. Joao Pesoa, Brazil: Universidade Federal da Paraiba. Retrieved from http://www.web.ca/ robrien/papers/arfinal.html 
[20] Richards, D., \& Cameron, L. (2008). Applying Learning Design concepts to problem-based learning. In L. Cameron \& J. Dalziel (Eds.), Learning Activity Management System, International Conference (p. 87-96). Sydney: LAMS Foundation.

[21] Saleh, M., Al Barghuthi, N., \& Baker, S. (2017). Innovation in Education via Problem Based Learning from Complexity to Simplicity. In 2017 International Conference on New Trends in Computing Sciences (ICTCS) (pp. 283-288). IEEE.

[22] Sedaghat, A., Al Shalabi, A., Eilaghi, A., \& Assad, M. E. H. (2018). Laptop riser, a useful PBL project for diploma students in engineering design. Journal of Problem Based Learning in Higher Education, 6(1), early view. doi: https://doi.org/10.5278/ojs.jpblhe.v0i0.2148

[23] Selçuk, G. S., \& Çalışkan, S. (2010). A small-scale study comparing the impacts of problem-based learning and traditional methods on student satisfaction in the introductory physics course. Procedia-Social and Behavioral Sciences, 2(2), 809-813.

[24] Turner, D. W. (2010). Qualitative interview design: A practical guide for novice investigators. The Qualilative Report, 15, 754-760.

[25] Utecht, J. R. (2003). Classroom, problem-based learning in the student centred. Retrieved from http://www.jeffutecht.com/docs/PBL.pdf. 